\title{
Servicios prestados por el Departamento de Análisis del IAPH a la Dirección General de siete Instituciones del Patrimonio Histórico. 1998-99
}

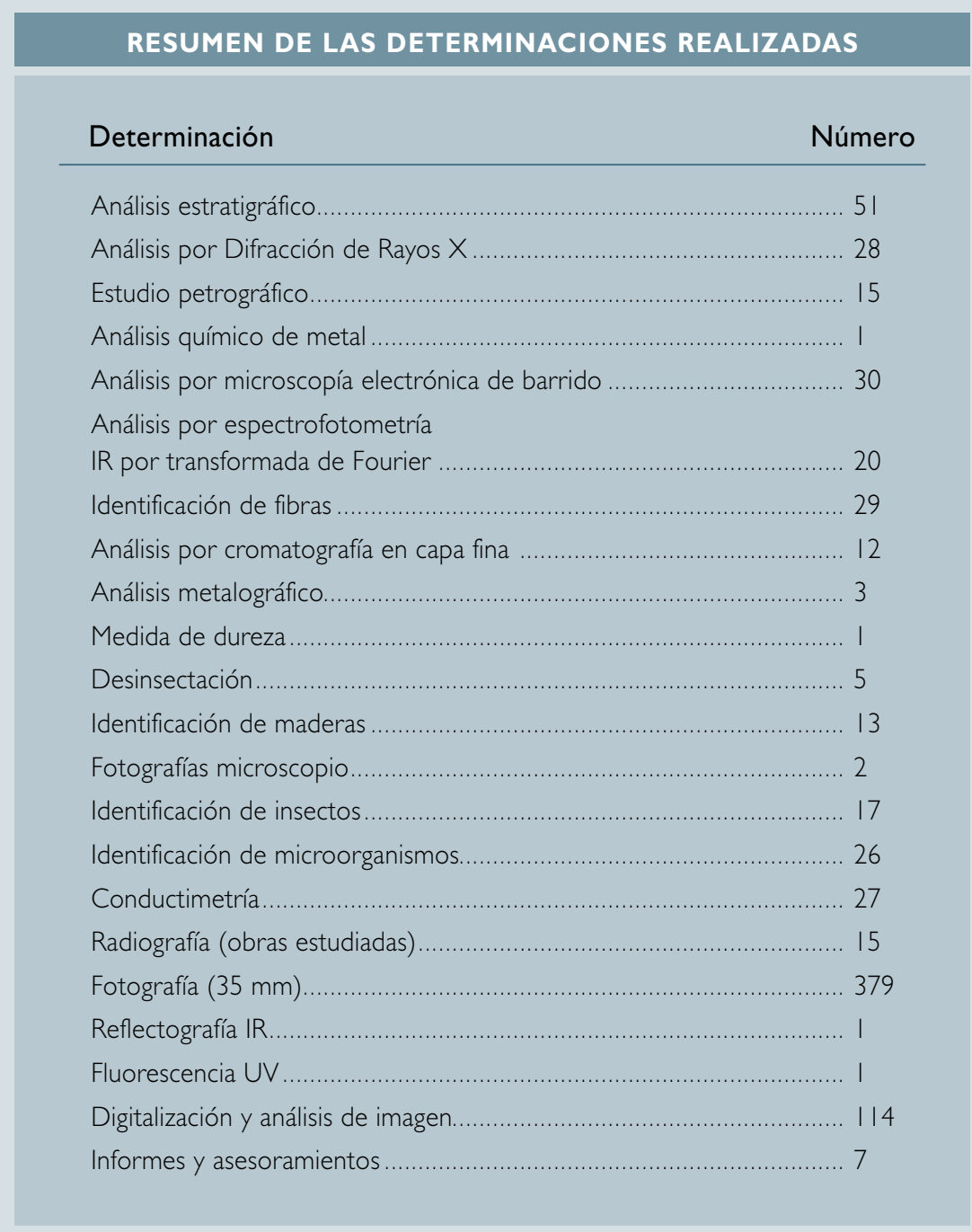

El Departamento de Análisis incorpora entre sus actividades la prestación de servicios relacionados con los estudios analíticos a la Dirección General de Instituciones del Patrimonio Histórico. Estos servicios se engloban dentro del Programa de Intervención en Bienes Culturales de las Instituciones del Patrimonio Histórico, Programa conjunto de ambos Organismos.

En los dos últimos años dichos servicios se han centrado en las siguientes actividades.

\section{Museo de Bellas Artes de Sevilla}

- Estudio analítico, radiográfico y fotográfico de La muerte del maestro, VILLEGAS CORDERO.

- Estudio sobre ataque biológico.

- Préstamo del equipo de desinfección del IAPH y realización de tratamientos a diversas obras.

- Revelado de las radiografías efectuadas en el Museo en las instalaciones del Laboratorio de Métodos de Examen del IAPH.

- Análisis de materiales de dos obras de LUCAS VALDÉS, Alegoría de la institución de la Orden Tercera y Santa Isabel de Hungría curando a una enfermo.
Museo Arqueológico de Sevilla

- Análisis de escarabajo egipcio procedente de excavación arqueológica de Coria del Río.

- Análisis de los materiales de capiteles árabes de mármol.

- Análisis de producto de tratamiento para piedra.

- Análisis de agua de extracción de sales

- Estudio analítico y gammagráfico de Tumba de Mulva

Museo de Bellas Artes de Córdoba

- Estudio sobre ataque biológico.

- Estudio analítico, radiográfico, reflectográfico y fluorescencia UV de San Nicolás de Bari, PEDRO DE CÓRDOBA.

- Radiografías de cuatro lienzos de ANTONIO DEL CASTILLO, Santa María Magdalena y Santa Catalina, Imposición de la CasuIla a San Ildefonso, San Vicente Ferrery Bautismo de San Francisco

- Estudio analítico, radiográfico y fotográfico de Óleo sobre cuero Cristo entre dos Santos Juanes

Conjunto Arqueológico de Madinat-al-Zahara

- Estudio analítico y fotográfico de 3 Aljimeces califales

Archivo Histórico Provincial de Jaén

- Asesoramiento sobre tratamientos contra insectos xilófagos.

- Análisis del producto de alteración de los paramentos exteriores del edificio del Archivo.

\section{Museo de Jaén}

- Redacción de informe sobre los posibles efectos perjudiciales de la aplicación de la fluorescencia de Rayos $X$ para el estudio de pigmentos en escultura ibérica.

Museo de Linares monográfico de Cástulo - Estudio analítico, radiográfico y fotográfico de 13 piezas de hierro del Centenillo 
Museo Arqueológico de Úbeda

- Estudio analítico y fotográfico de Dos Kylix

Museo de Cádiz

- Estudio analítico y fotográfico del Tapiz de Telémaco

- Estudio biológico de Beato Juan de Hougton, ZURBARÁN.

- Radiografía de dos lienzos de ZURBARÁN, Pentecostés y La Porciúncula

\section{Conjunto Arqueológico de Baelo Claudia}

- Análisis de muestras de la prospección subacuática

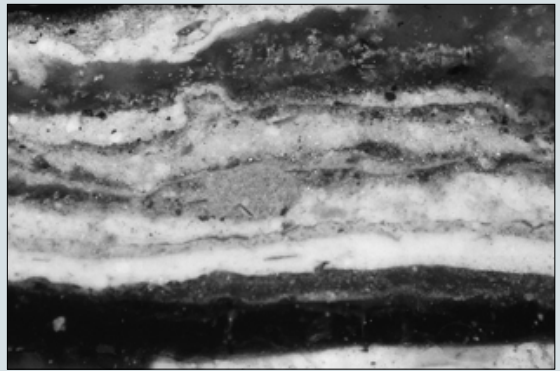

Museo de Bellas Artes de Granada

- Estudio analítico de Cristo atado a la columna con San Pedro arrepentido, JUAN DE ARAGÓN.
- Estudio radiográfico de Cabeza de San Juan de Dios, ALONSO CANO.

\section{Museo de Huelva}

- Estudio analítico, radiográfico y fotográfico de Rueda hidráulica romana

\section{Museo de Málaga}

- Estudio analítico, radiográfico y fotográfico de Virgen aparecida y San Antonio de Padua

Rosario Villegas Sánchez

\section{Equipamiento técnico del taller de material arqueológico del IAPH}

El taller de Material Arqueológico es la instalación más reciente del I.A.P.H.. Con este ámbito se amplia el campo de actividad en conservación-restauración de bienes muebles a los materiales de procedencia arqueológica de pequeño, mediano y gran formato.

El programa de uso definido para este taller permite abordar el proceso completo de examen, diagnóstico, intervención en un bien cultural de grandes dimensiones. Esta concepción de partida, unida al hecho que será el ámbito espacial donde se va a desarrollar la intervención de la escultura en bronce "El Giraldillo", ha dirigido la dotación técnica e instrumental del taller hacia una vertiente eminentemente práctica y operativa, pero a su vez versátil, a fin de compatibilizar los recursos técnicos y económicos existentes con las necesidades y compromisos adquiridos por el I.A.P.H. en su programación anual.

De tal forma que en su dotación se ha tenido en cuenta tanto las necesidades y exigencias de los bienes que se están estudiando e interviniendo en la actualidad, como los requerimientos específicos del Giraldillo.

Por necesidades técnicas y operativas no existe compartimentación fija del único ambiente en el que se ha diseñado el taller ( 13 , $60 \mathrm{~m}$ de largo $\times 10,50 \mathrm{~m}$ de ancho $\times 6,00$ $\mathrm{m}$ de altura), pero sí se ha previsto su distribución interior en diferentes áreas que permiten abarcar el ciclo de trabajo completo de los bienes culturales para los que se ha concebido el taller. Estas áreas de trabajo se articulan como sigue:

- Área de despacho y redacción de informes compuesta por mesas, armarios de oficina y ordenador.

- Área de diagnóstico: equipada con endoscopio, lupa binocular, equipo completo de fotografía, registro en vídeo y vídeo impresora, negatoscopio, equipo de iluminación auxiliar con o sin aumentos de trabajo, colorímetro, etc.

- Área de trabajo en húmedo o con emisión de polvo, dotada de sistema de agua fría, caliente y desmineralizada, equipo de limpieza a vapor y nebulización, microchorro de arena, etc.

- Área de trabajo en seco. Equipada con bancos de trabajo, material de vidrio de laboratorio, herramientas y maquinaria de carpintería, calefactores, aspiradora, microtornos, vibroincisor, pirógrafo, agitador, magnético, balanza, termómetro de contacto, conductímetro, estufa de desecación, compresor de aire comprimido, armarios para productos y disolventes, etc.

Por último el taller dispone de sistema de control microclimático y de seguridad, así como equipamiento fijo y móvil que permite desplazar las obras por las diferentes áreas de trabajo (puentes grúas de 1000 kg y 5000 kg de carga y grúa móvil de 1000 kg), acceder a la obra en su conjunto (escaleras y andamios) o al interior del taller (muelle de carga-descarga).

Tanto en la distribución espacial como en la elección del mobiliario básico de las áreas de trabajo ha primado sobre todo la movilidad y versatilidad con objeto de que sea el taller y su equipamiento el que se adapte a las necesidades de las piezas y no a la inversa, esta filosofía de partida nos permite abordar los trabajos comprometidos actualmente, así como los que en un futuro pudiesen ser objeto de encargo al Instituto.

Mª José González López 